\title{
Inadequate uric acid referent values may cause "hyperuricemia" and overtreatment
}

\author{
Furlan $\mathrm{SZ}^{1 *}$, Rumboldt $\mathrm{M}^{2}$, Tomičić $\mathrm{M}^{3}$ and Rumboldt $Z^{4}$ \\ ${ }^{1}$ Split-Dalmatia County Health Center, Department of Family Medicine, Kavanjinova 2, Split, Croatia \\ ${ }^{2}$ School of Medicine, University of Split, Department of Family Medicine, Šoltanska 2, Split, Croatia \\ ${ }^{3}$ School of Medicine, University of Split, Department of Family Medicine, Šoltanska 2, Split, Croatia \\ ${ }^{4}$ School of Medicine, University of Split, Šoltanska 2, Split, Croatia
}

\begin{abstract}
Aim: The current serum uric acid upper reference limits in Croatia are seemingly too low $(337 \mu \mathrm{mol} / 1$ for women and $403 \mu \mathrm{mol} / 1)$, as in a pilot study we have found much higher values (at least 390 and $488 \mu \mathrm{mol} / \mathrm{l}$, respectively). As low reference standards may stimulate overdiagnosis and overtreatment, these data motivated us for a larger sample investigation.

Method: This cross-sectional, population-based study was conducted retrospectively (2013 data) in the archives of two accredited biochemistry laboratories in Split, Croatia (uricase method, Olympus analyzers). Assessed were consecutive, anonymized results from all adult individuals ( $\geq 18$ years), stratified in percentiles by age and gender.

Result: Among 1,565 results (844 female, 721 male) the prevalence of hyperuricemia, defined by the actual upper reference intervals in Croatia, steadily increases with age from $2 \%$ to over $30 \%$, amounting at $40 \%$ in both genders after the age of 80 years.

Conclusion: The actual upper reference interval limits for uric acid are too low, derived from samples that do not represent the actual southern Croatian population and do not include age stratification above 18 years. There is a need for new, higher, age and gender grounded limits of serum uric acid "normality" in a Mediterranean population.
\end{abstract}

\section{Introduction}

Uric acid is the final purine decomposition product in humans [1]. It is a biologically active molecule, one of the most powerful antioxidants [2]. Nevertheless, in atherogenesis it becomes paradoxically pro-oxidant, even at the upper third of the physiological range [3]. This paradox is further enhanced by tissue alterations, such as lowered local $\mathrm{pH}$ or lack of other antioxidants [4]. Indeed, the Framingham study showed that uric acid might be an atherosclerosis risk indicator because of its links with arterial hypertension, dyslipidemia and glucose metabolism disorders [4]. Lambert et al. [5] have identified hyperuricemia as an early indicator of cardiovascular disorders in obese people only. On the other hand, when the uric acid level is too low, its antioxidant role is reduced, resulting in a "U" shaped cardiovascular risk curve as described, for example, in the PIUMA study [6]. When hypertensive people decrease their uricemia below $269 \mu \mathrm{mol} / \mathrm{l}(<4.5 \mathrm{mg} / \mathrm{dl})$ in men and below 191 $\mu \mathrm{mol} / \mathrm{l}(<3.2 \mathrm{mg} / \mathrm{dl})$ in women, a significant increase in cardiovascular risk is observed [7-10]. Some studies have shown potential benefits in starting hypouricemic therapy if other cardiovascular risk factors are combined with elevated serum uric acid levels, which is not generally accepted [3-7].

How to define hyperuricemia? The reference intervals (RIs) for serum uric acid, and other laboratory results as well, are mostly based on younger volunteer samples, and the distribution presented in terms of percentiles or arithmetic means with standard deviations, which usually labels the 5\% extremes as "pathological". However, it must be kept in mind that the RIs are descriptive figures of a sampled population and should not be confused with clinical decision limits (CDLs), i.e. levels at which a therapeutic intervention is justified. Indeed, low RIs and confounding of RIs with CDLs often leads to overdiagnosis and overtreatment, converting healthy or at least asymptomatic people into patients [8]. Such mistakes are particularly relevant among the elderly since with aging the expected serum uric acid levels increase [2-4]. The current, official reference intervals (RIs) in Croatia are set at 134-337 $\mu \mathrm{mol} / \mathrm{l}$ for women and 182-403 $\mu \mathrm{mol} / \mathrm{l}$ for men, derived from a northern Croatian sample (Zagreb region), analyzed over 25 years ago, and with no age stratification above 20 years [9,10,11]. Regional differences in uric acid concentration may be quite large, as recently shown in China [12]. Other sources quote quite different RIs, for example the Wallach's textbook [13] sets the limits at 113-446 $\mu \mathrm{mol} / \mathrm{l}$ (1.9-7.5 mg/dl) for women and 149-476 $\mu \mathrm{mol} / \mathrm{l}(2.5-8 \mathrm{mg} / \mathrm{dl})$ for men.

Over the last few years the authors of this report were consulting a growing number of asymptomatic patients labeled hyperuricemic according to the national RIs. Presuming that this overdiagnosis trend, favoring hasty, unwarranted medicalization was due to inadequately low upper RI limits, we have planned to assess the actual distribution of

*Correspondence to: Sanja Žižić Furlan, Split-Dalmatia County Health Center, Department of Family Medicine, Kavanjinova 2, Split, Croatia, Tel: 0038595 9084444; E-mail: sanjazuzic@yahoo.co.uk

Key words: uric acid, reference values, hyperuricemia

Received: July 02, 2018; Accepted: July 11, 2018; Published: July 16, 2018 
uricemia in family medicine patients scheduled for routine laboratory tests. In a pilot study on 60 female and 60 male serum samples we have found the average uric acid values of $297 \pm 93 \mu \mathrm{mol} / \mathrm{l}$ for the female, and $376 \pm 111 \mu \mathrm{mol} / \mathrm{l}$ for the male gender, corresponding to upper limits of at least 390 and $488 \mu \mathrm{mol} / \mathrm{l}$ (i.e. mean +1 standard deviation), prompting us for a larger sample study.

\section{Material and method}

This observational, cross-sectional study was designed to analyze the distribution of plasma uric acid levels noted down during 2013 in the registries of two accredited biochemistry laboratories [14] in Split-Dalmatian county, a Mediterranean region of Croatia with some 450,000 inhabitants. Both laboratories used enzyme colored quantitative method on Olympus analyzers. The photometric quantification of uric acid concentration was based on uricase, converting uric acid to alantoin and hydrogen peroxide, producing a chromophore, measured at a wavelength of $660 / 800 \mathrm{~nm}$.

The study was approved by the Split-Dalmatian County Health Center's Ethics Committee. This board decided that individual informed consent was not necessary for this investigation since the laboratory tests were not performed for the study's own sake, common practice does not require patient consent for standard lab testing, and the data were anonymous, related to the healthcare code numbers only.

Analyzed were the laboratory records of uric acid plasma concentration from adult examinees ( $\geq 18$ years; only age and sex data were available), registered from January 1, 2013 to December 31, 2013. Multiple results were eliminated; only one randomly selected test result per patient was processed. The results were tabulated in Microsoft Office Excel and processed statistically with SPSS 17.0.1 (SPSS Inc., Chicago, IL, USA). As mentioned, the current Croatian RIs range from 134 to $337 \mu \mathrm{mol} / \mathrm{l}(2.2-5.7 \mathrm{mg} / \mathrm{dl})$ for women and from 182 to $403 \mu \mathrm{mol} / \mathrm{l}$ (3.0-6.8 mg/dl) for men'. For the sake of this study on top of those figures we have added two higher, arbitrary limits, derived from our pilot study and literature data $[2-7,9,13]$, set at $\geq 380 \mu \mathrm{mol} / \mathrm{l}$ for women and $\geq 430 \mu \mathrm{mol} / \mathrm{l}$ for men. Since the distribution of values significantly deviated from normal (Kolmogorov-Smirnov test, $\mathrm{P}=0.023$ ), the $\chi^{2}$ test or Mann-Whitney $\mathrm{U}$ test, as appropriate were used for statistical comparisons, and significant was considered $\mathrm{P}<0.05$.

\section{Result}

As shown in the flow diagram (Figure 1) analyzed were 2,072 recorded serum samples along with sex and age data. Since 507 records were either redundant (repetitive, control measurements) or the data on age/gender were questionable or missing, analyzed were 1,565 records (75.5\% of the original sample); 844 (53.9\%) from women and $721(46.1 \%)$ from men. Age range was 18 to 102 years with the median of 62 years.

Table 1 shows that the results obtained in female subjects were often above the upper national RIs (i.e. $\geq 337 \mu \mathrm{mol} / \mathrm{l}$ ) and even surpassing our preset limits (i.e. $\geq 380 \mu \mathrm{mol} / \mathrm{l}$ ), especially among the elderly. A steady, although uneven increase by age was observed in almost all the strata (Mann-Whitney $\mathrm{U}=53.0$; $\mathrm{P}<0.025$ ), particularly after 50 years of age $\left(\chi^{2}=14.67 ; \mathrm{P}<0.001\right)$. The values obtained from the male examinees (Table 2) were even higher and often overcame not only the 403 but also the $430 \mu \mathrm{mol} / \mathrm{l}$ upper border. A steady, albeit less steep increase was again observed across the age subgroups (e.g. $\chi^{2}=20.67 ; \mathrm{P}<0.001$ for the strata $40-49$ vs. 50-59). Table 3 shows the age-related, growing prevalence of formally defined hyperuricemia. For example, among women the rate of uricemia $\geq 337 \mu \mathrm{mol} / \mathrm{l}$, increases from 2 to $46 \%$ depending on age, and in men values $\geq 403 \mu \mathrm{mol} / \mathrm{l}$ are seen in up to $39 \%$. In most age strata the levels of uricemia are significantly higher in men (Mann-Whitney $\mathrm{U}=52.1 ; \mathrm{P}=0.026$ ). The observed uric acid concentrations largely surpass the current national upper RIs $\left(\chi^{2}=\right.$ 109.64; df 3; $\mathrm{P}<0.001$ ), and even our tentative limits of $380 \mu \mathrm{mol} / \mathrm{l}$ for women and $430 \mu \mathrm{mol} / \mathrm{l}$ for men (Figure 2).

\section{Discussion}

How best to determine the most acceptable laboratory reference values ("cut-off points") to facilitate the everyday practice? There are several approaches to this problem and no one is quite satisfactory



Figure 1. Flow chart of the study

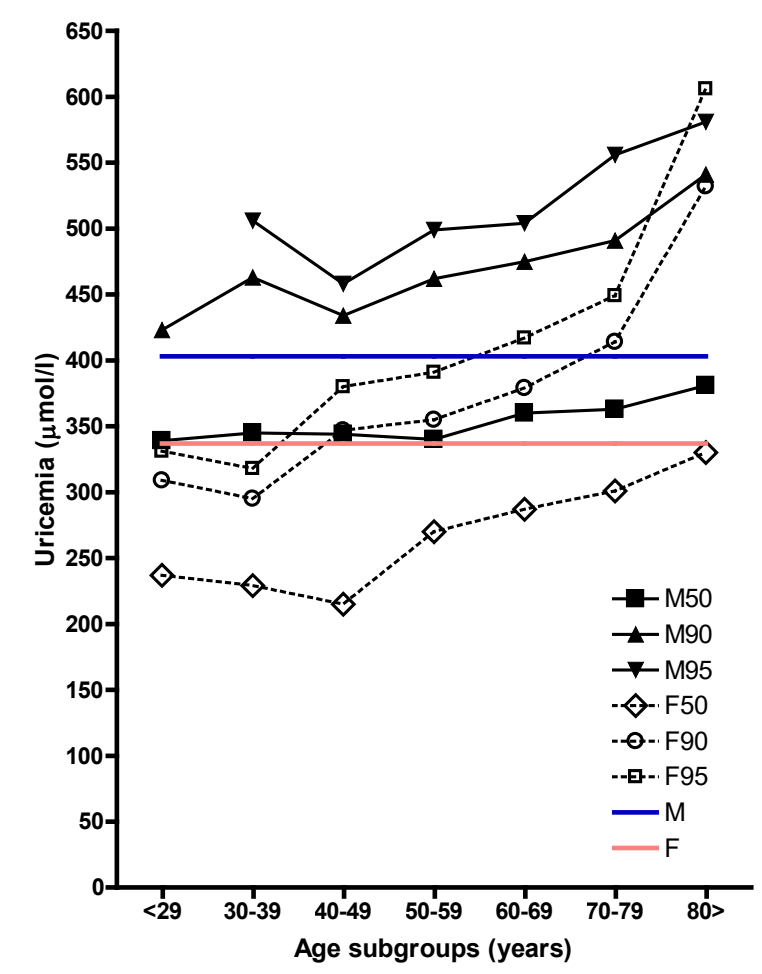

Figure 2. Distribution of upper plasma uric acid levels in Split,Croatia $(N=1,565)$ presented are some relevant percentiles. Legend: $\mathrm{M}$ stands for male, $\mathrm{F}$ for the female gender, and the numbers 50,90, and 95 symbolize the respective percentiles. Horizontal $\mathrm{M}$ and $\mathrm{F}$ lines represent the official upper reference limits in Croatia (403 and $337 \mu \mathrm{mol} / \mathrm{l})$. 
Table 1. Percentile distribution of uricemia by age, women $(\mathrm{N}=844)$

\begin{tabular}{|c|c|c|c|c|c|c|c|c|}
\hline \multirow{2}{*}{$\begin{array}{c}\text { Age } \\
\text { (years) }\end{array}$} & \multirow{2}{*}{$\mathbf{N}$} & \multicolumn{7}{|c|}{ Percentile } \\
\hline & & $5^{\text {th }}$ & $10^{\text {th }}$ & $25^{\text {th }}$ & $\mathbf{5 0}^{\text {th }}$ & $75^{\text {th }}$ & $90^{\text {th }}$ & $95^{\text {th }}$ \\
\hline $18-29$ & 50 & 167.0 & 182.7 & 205.3 & 237.0 & 273.8 & 309.1 & 330.9 \\
\hline $30-39$ & 60 & 143.0 & 171.2 & 197.3 & 228.5 & 260.8 & 294.5 & 317.9 \\
\hline $40-49$ & 86 & 143.7 & 157.0 & 180.5 & 214.5 & 266.5 & 347.2 & 379.7 \\
\hline $50-59$ & 175 & 154.2 & 183.6 & 221.0 & 269.0 & 319.0 & 355.0 & 390.6 \\
\hline $60-69$ & 200 & 198.1 & 216.1 & 242.0 & 286.0 & 324.0 & 378.9 & 416.9 \\
\hline $70-79$ & 176 & 170.8 & 198.1 & 251.0 & 301.0 & 362.8 & 413.6 & 448.7 \\
\hline $80-102$ & 97 & 205.6 & 229.4 & 268.0 & 330.0 & 428.0 & 531.6 & 606.6 \\
\hline
\end{tabular}

Table 2. Percentile distribution of uricemia by age, men ( $\mathrm{N}=721)$.

\begin{tabular}{|c|c|c|c|c|c|c|c|c|}
\hline \multirow{2}{*}{$\begin{array}{c}\text { Age } \\
\text { (years) }\end{array}$} & \multirow{2}{*}{$\mathbf{N}$} & \multicolumn{7}{|c|}{ Percentile } \\
\hline & & $5^{\text {th }}$ & $10^{\text {th }}$ & $25^{\text {th }}$ & $50^{\text {th }}$ & $\mathbf{7 5}^{\text {th }}$ & $90^{\text {th }}$ & $95^{\text {th }}$ \\
\hline $18-29$ & 18 & 203.0 & 250.7 & 306.5 & 339.0 & 377.3 & 423.2 & $* *$ \\
\hline $30-39$ & 45 & 217.9 & 221.8 & 287.0 & 345.0 & 416.5 & 462.6 & 505.9 \\
\hline $40-49$ & 93 & 204.8 & 238.4 & 291.0 & 344.0 & 380.0 & 434.4 & 458.1 \\
\hline $50-59$ & 147 & 222.2 & 245.0 & 288.0 & 340.0 & 394.0 & 462.2 & 499.2 \\
\hline $60-69$ & 202 & 231.2 & 267.2 & 309.0 & 359.5 & 415.8 & 475.0 & 503.7 \\
\hline $70-79$ & 149 & 222.0 & 263.0 & 312.5 & 363.0 & 431.0 & 491.0 & 555.5 \\
\hline $80-102$ & 67 & 245.0 & 266.6 & 323.0 & 381.0 & 450.0 & 541.2 & 581.4 \\
\hline
\end{tabular}

** 95th percentile is not shown because of the low number of subjects.

Table 3. Percentual prevalence of hyperuricemia by age and gender $(\mathrm{N}=1,565)$

\begin{tabular}{|c|c|c|c|c|c|c|}
\hline $\begin{array}{c}\text { Age } \\
\text { (years) }\end{array}$ & $\begin{array}{c}\text { Female } \\
>337 \mu \mathrm{mol} / \mathrm{l}\end{array}$ & $\begin{array}{c}\text { Female } \\
>380 \mu \mathrm{mol} / \mathrm{l}\end{array}$ & $\begin{array}{c}\text { Male } \\
>403 \mu \mathrm{mol} / \mathrm{l}\end{array}$ & $\begin{array}{c}\text { Male } \\
>\mathbf{4 3 0} \mu \mathrm{mol} / \mathrm{l}\end{array}$ & Female and male $>R^{A}$ & Female and male $>R I^{B}$ \\
\hline $18-29$ & $2 \%$ & 0 & $17 \%$ & $6 \%$ & $6 \%$ & $2 \%$ \\
\hline $30-39$ & $2 \%$ & 0 & $29 \%$ & $20 \%$ & $14 \%$ & $9 \%$ \\
\hline $40-49$ & $9 \%$ & $4 \%$ & $15 \%$ & $10 \%$ & $12 \%$ & $7 \%$ \\
\hline $50-59$ & $16 \%$ & $6 \%$ & $25 \%$ & $18 \%$ & $20 \%$ & $12 \%$ \\
\hline $60-69$ & $20 \%$ & $9 \%$ & $27 \%$ & $20 \%$ & $23 \%$ & $14 \%$ \\
\hline $70-79$ & $36 \%$ & $19 \%$ & $34 \%$ & $26 \%$ & $35 \%$ & $22 \%$ \\
\hline $80-102$ & $46 \%$ & $32 \%$ & $39 \%$ & $30 \%$ & $43 \%$ & $31 \%$ \\
\hline Total & $22 \%$ & $11 \%$ & $27 \%$ & $20 \%$ & $24 \%$ & $15 \%$ \\
\hline
\end{tabular}

$\mathrm{RI}^{\mathrm{A}}=$ women $\geq 337 \mu \mathrm{mol} / 1$, men $\geq 403 \mu \mathrm{mol} / 1 ; \mathrm{RI}^{\mathrm{B}}=$ women $\geq 380 \mu \mathrm{mol} / 1$, men $\geq 430 \mu \mathrm{mol} / 1$.

$[8,10,12,13]$. Statistical definition of hyperuricemia determines the boundary to healthy individuals at the level of the population sample's upper decile, $95^{\text {th }}$ percentile or $99^{\text {th }}$ percentile. One or two standard deviations above the calculated arithmetic mean may also be used in this sense if the obtained distribution can be considered "normal", i.e. consistent with the Gaussian dispersion. Such delimitations are, of course, descriptive, formal and voluntaristic, designating a segment of a seemingly healthy population as "sick" (and some patients with "normal" findings as "healthy"). Our results indicate that the overall prevalence of such, statistically defined hyperuricemia in Split is well over $20 \%$, and more prevalent among men. Female patients show a marked increase in uricemia after menopause, which was recently confirmed by another study in southern Croatia [15]. In our population such "hyperuricemia" may be detected in more than 1 out of 5 persons below 60 years and in more than 1 out of 3 in people over 60 years of age! It is almost impossible to set a limit above which the potential health threat becomes socially or medically relevant. The limit may be determined by clinical criteria (CDLs; therapeutic, operational), based on the ratio of proven benefit vs. the expected untoward effects and cost of a presumed intervention. Additional problem concerns the nature of evidence, i.e. which sample was used to produce the data? Was it large enough and representative of all the population strata? Which approach is more appropriate? We are unable to offer a clear response, but some hints are deducible from our results: serum uric acid values in Dalmatia, i.e. in southern Croatia are significantly above the current RIs, especially among the elderly. Similar results have been obtained in other countries; for example, the upper $95 \%$ percentile RI limit in north-eastern India is estimated at $428 \mu \mathrm{mol} / \mathrm{l}$ for women and $488 \mu \mathrm{mol} / \mathrm{l}$ for men [16]. Canadian upper limits for the $13-79$ years range have been determined at $369 \mu \mathrm{mol} / \mathrm{l}$ for women and at $458 \mu \mathrm{mol} / \mathrm{l}$ for men [17]. The mentioned Chinese study ${ }^{12}$ has shown a remarkable regional variability in plasma uric acid upper limits: from 394 to 474 $\mu \mathrm{mol} / \mathrm{l}$ for the female, and from 495 to $599 \mu \mathrm{mol} / \mathrm{l}$ for the male gender. According to these data and our results, there is a need for new RIs, reflecting actual, age and gender grounded levels in a Mediterranean population. Moreover, the RIs must not be equalized with CDLs, which are quite different, based upon discrepant presumptions: the former are descriptive, and the latter are interventional.

\section{Study limitations}

Our research was observational, using a convenience sample, and examined were only the available data, with no way to verify their validity or representativeness. The sample was analyzed without information about possible comorbidities and medications which could influence uric acid levels, so that the observed results may be higher than in a properly selected, randomized sample of apparently healthy individuals. Moreover, because of missing or duplicate data, we had to exclude more than 500 results (507 out of 2072 or $24.5 \%$ ). On the other hand, its advantage is the large amount of all the available data, which 
may faithfully reflect Split population, i.e. all the persons who, with other laboratory tests, had uric acid levels determined in their plasma.

\section{Conclusion}

1. Statistical calculations of RIs in case of serum uric acid levels were often based on samples not representative of the actual population and did not include age stratification. According to our results the official Croatian upper borderline of $337 \mu \mathrm{mol} / \mathrm{l}$ for women and 403 $\mu \mathrm{mol} / \mathrm{l}$ for men should be set much higher, presumably above 390 and $490 \mu \mathrm{mol} / \mathrm{l}$ respectively, and reflect the important impact of advancing age.

2. One of the main Hippocratic values is "first do not harm", which is particularly true for asymptomatic patients. With all the clinical data, bearing in mind valid guidelines, a positive therapeutic decision should be made if its expected gains overrule the possible shortcomings. The initial level of such intervention in case of hyperuricemia is not clearly defined but should be set markedly above the statistically defined upper reference limits.

\section{Acknowledgement}

This work was not sponsored/supported by any private or public foundation. The enclosed manuscript has not been published in this or a substantially similar form (in print or electronically, including on a web site), nor accepted for publication elsewhere, nor it is under consideration by another publication.

\section{References}

1. Maiuolo J, Oppedisano F, Gratteri S, Muscoli C, Mollace V (2016) Regulation of uric acid metabolism and excretion. Int J Cardiol 213: 8-14. [Crossref]

2. Becker MA (2017) Pathophysiology of gouty arthritis. UpToDate.

3. Borghi C, Rosei EA, Bardin T, Dawson J, Dominiczak A, et al. (2015) Serum uric acid and the risk of cardiovascular and renal disease. J Hypertens 33: 1729-1741. [Crossref]

4. Culleton BF, Larson MG, Kannel WB, Levy D (1999) Serum uric acid and risk for cardiovascular disease and death: the Framingham Heart Study. Ann Intern Med 131: 7-13. [Crossref]
5. Lambert EA, Hachem M, Hemmes R, Straznicky NE, Eikelis N, et al. (2017) Serum uric acid and the relationship with subclinical organ damage in adults. J Hypertens 35 : 745-752. [Crossref]

6. Verdecchia P, Schillaci G, Reboldi G, Santeusanio F, Porcellati C, et al. (2000) Relation between serum uric acid and risk of cardiovascular disease in essential hypertension. The PIUMA study. Hypertension 36:1072-1078. [Crossref]

7. Kuwabara M (2016) Hyperuricemia, cardiovascular disease, and hypertension. Pulse (Basel) 3: 242-252. [Crossref]

8. Llor C (2017) Reducing overdiagnosis in primary care is needed. Eur J Gen Pract 23 215-216. [Crossref]

9. Harmonization of general search in field of general medical biochemistry. In Stavljeniic Rukavina A, Cvorišcec D, Eds. Harmonization of laboratory findings in the field of general, special and high-differentiated medical biochemistry. 2nd Ed. Zagreb: Medicinska naklada, 2007:11-20. (in Croatian)

10. Flegar-Meštric Z, Tadej D, Vrhovski-Hebrang D (1993) Preliminary report. Reference intervals of 56 hematological and biochemical constituents of blood and serum for reference individuals corresponding to "reference state" - population of Zagreb. Croat Med J 34:163-169.

11. Flegar-Meštric Z, Jagarinec N, Surina B (1996) Referent values of serum biochemica components among school children and youth in Zagreb. Biochem Med 6: 277-288.

12. Xia L, Chen M, Liu M, Tao Z, Li S, et al. (2016) Nationwide multicenter reference interval study for 28 common biochemical anylates in China. Medicine 95: e2915. [Crossref]

13. Williamson MA, Snyder LM, Wallach JB (2011) Wallach's interpretation of diagnostic tests. 9th ed. Philadelphia: Wolters Kluwer/Williams \& Wilkins.

14. Flegar-Meštric Z, Nazor A, Perkov S, Surina B, Kardum-Paro MM, et al. (2010) Accreditation of medical laboratories in Croatia - experiences of the Institute of Clinical Chemistry, University Hospital "Merkur", Zagreb. Coll Antropol 34:181-186. [Crossref]

15. Jeroncic-Tomic I, Pranic S, Mulic R, Polašek O (2017) Comparison of the incidence of hyperuricemia and gout between Korcula and Vis islands and the city of Split including its surroundings. Lijec Vjesn 139:144-149. (In Croatian)

16. Das M, Borah NC, Ghose M, Choudhury N (2014) Reference Ranges for Serum Uric Acid among Healthy Assamese People. Biochem Res Int 2014: 171053. [Crossref]

17. Adeli K, Higgins V, Nieuwesteeg M, Raizman JE, Chen Y, et al. (2015) Biochemical marker reference values across pediatric, adult, and geriatric ages: establishment of robust pediatric and adult reference intervals on the basis of Canadian Health Measures Survey. Clin Chem 61:1049-1062. [Crossref]

Copyright: (C2018 Furlan SZ. This is an open-access article distributed under the terms of the Creative Commons Attribution License, which permits unrestricted use, distribution, and reproduction in any medium, provided the original author and source are credited. 